\title{
Language in Educational Contexts
}

\author{
Natalie Keefer* \\ University of Louisiana at Lafayette \\ Michelle Haj-Broussard \\ University of Louisiana at Lafayette \\ *Corresponding Author: natalie.keefer@louisiana.edu
}

d.

DOI: $10.46303 /$ jcve.2020.9

\begin{abstract}
How to cite this paper: Keefer, N., \& Haj-Broussard, M. (2020). Language in Educational Contexts. Journal of Culture and Values in Education, 3(2), 1-12. doi.org/10.46303/jcve.2020.9

This is an Open Access article distributed under the terms of the Creative Commons Attribution 4.0 International license (https://creativecommons.org/licenses/by/4.0/)
\end{abstract}

\section{Abstract}

The purpose of this special issue is to provide a space for scholars to disseminate theory and research about the influence of language in educational contexts. In this issue, we curated articles that address topics related to how language serves as a defining or decisive factor in education and schooling. In our introduction to this special issue, we provide an interpretive overview of the articles and offer an explanation of their relevance for understanding the complex nature of contemporary education. Salient topics include: critical analysis of discourse, linguistic landscapes, Natural Semantic Metalanguage, language ideology, politics and educational funding, funds of knowledge/identity, and definitional caveats related to language learning pedagogies in divergent contexts.

Keywords: linguistic theory and methods, language ideology, language learning practices

\section{Introduction}

Language is a value-laden hallmark of culture, as a symbol of ethnicity, race, immigrant status, social class, gender, and political beliefs. Language can be used as a weapon to wield power over oppressed people, as an instrument for resistance, or as a tool to empower people with words of inspiration. As such, how language is used and perceived in educational contexts, and the messages that language communicates, have implicit and explicit consequences for educators, students, and communities. How language is used to frame the process of education at the national, local, and state levels reveals socio-political sentiments about schooling and communities involved in the process of schooling. Additionally, whether or not students have access to second language learning opportunities in bilingual or immersion programs is heavily implicated in national, state, and local politics. In our introduction to the special issue, we provide an interpretive overview of the articles and offer an explanation of their relevance for understanding the complex nature of contemporary education. 


\section{Theory and Method for Linguistic Analysis in Education}

The social sciences, specifically the fields of linguistic anthropology and sociolinguistics, enrich our understanding of how language intersects and shapes informal and formal education. Within the study of language, theory and methods for conducting research for examining specific aspects of linguistic phenomena are closely intertwined and specialized. Several authors in this issue employ specialized frameworks and methods for linguistic analysis such as Natural Semantic Metalanguage, critical discourse analysis, and linguistic schoolscapes in order to reveal how people interpret and communicate meaning in educational contexts (Bernardo-Hinesley; Honegger; Johnson; Morales \& Bardo, in this volume).

\section{Ideology and Discourse}

At the heart of people's use of language to interpret and communicate meaning are discourses that define ideologies about language and schooling. Discourse refers to the ways we communicate narratives, explanations, concepts, myths, and ideologies that symbolize a particular perspective (Sensoy \& DiAngelo, 2017). For example, deficit-laden perspectives, including myths about people living in poverty, are framed through discourses that stereotype this social group as linguistically deficient, lazy, and apathetic of their children's schooling (Gorski, 2008). Conversely, asset-based perspectives, such as funds of knowledge and funds of identity, intentionally employ language as a tool to refocus discourses on existing strengths, including abundant and diverse knowledge, within families and communities of color (González, Moll, \& Amanti, 2005; Guerra et al., in this issue). Chung (in this issue) notes that parents' complex attitudes about second language acquisition are shaped by language ideologies and embodied in their discourse. As essential stakeholders, parental support has the capacity to determine the success of language immersion programs (Chung, in this issue; HajBroussard et al., 2019).

A pertinent way discourse communicates ideology is through reflexive discourses about language ideology. Language ideology refers to people's beliefs about language, including explanations of appropriate language structure and use, ideas about social and linguistic relationships, and moral and political interests (Diaz \& Hall, 2020; Woolard \& Schieffelin, 1994). Most broadly, language ideology encompasses "shared bodies of common sense notions about the nature of language in the world" (Woolard \& Schieffelin, 1994, p. 57). At the federal and state levels, language ideologies shape schooling through the creation of bodies of legislation that steer and/or restrict funding for language education policies (Başok \& Sayer, in this issue; Diaz \& Hall, 2020). Discourses that frame language ideologies are thus embodied and codified in legislation that regulates language in educational contexts. These discourses, and the language ideologies they communicate, contribute to the creation and maintenance of an imbalance of power, and thus, socio-economic and educational relationships frequently defined by oppression and exploitation (Fairclough, 2013). As Başok and Sayer (in this issue) demonstrate, in the United States ideological tensions are largely shaped by pluralist and assimilationist beliefs about language. Educators are frequently constrained by federal and state funding for language programs, especially when assimilationist policies are favored by the prevailing political party. Unfortunately, when language learning programs are defunded there are significant repercussions for students, including the exacerbation of language-related achievement gaps (Soland, 2019). 


\section{Critical Discourse Analysis}

For several decades, education researchers have used critical discourse analysis (CDA) to make sense of how people use language to create meaning in educational contexts (Rogers et al., 2005). Johnson (in this issue) employs CDA to demonstrate the utility, and culturally relevant and sustaining suitability, of battle rap in the language arts and social studies curriculum. In his article, Johnson argues battle rap offers an opportunity to engage Black students with social studies content in a way that affirms their experiences in society. Furthermore, integrating insightful excerpts of socially conscious battle raps into the curriculum can be a powerful device for fostering students' critical consciousness. Johnson framed his assertion through the lens of critical discourse analysis because this method allows for an elegant dissection of how socio-historic conditions inspire people of color to produce discourses that communicate critical social awareness and social studies content knowledge. A critical discourse analysis of battle rap as an underutilized and overlooked educational resource also supports the claim that all analyses of language are inherently critical, because not all social practices (including language) are created and treated equally (Rogers et al., 2005, p.367).

\section{Linguistic Schoolscapes}

Spatial analysis of language is another method that researchers use to demonstrate the powerful influence of language ideologies in educational contexts. Linguistic landscape studies investigate the spatial use of language, particularly the "visibility and salience of languages on public and commercial signs" in a given place (Landry \& Bourhis, 1997, p. 23). Foremost, it is important to acknowledge linguistic landscape analysis in an educational context cannot be separated from the historical and political factors that have shaped the structure and function of place (Blommaert, 2013; Webster, 2014). As Gorter (2018) noted, linguistic schoolscapes have distinct characteristics from other public spaces. For example, signs in schools are unique in their intent to communicate subject knowledge and multiple literacies, convey values aligned with effective citizenship, establish rules and norms for behavior in schools, as well as to provide practical information to educators, students, and families. Of crucial importance is the role school signage has in acknowledging language ideology by signifying the acceptance and presence, or exclusion, of multiple languages within its boundaries.

Bernardo-Hinesley (in this issue) extols the use of linguistic schoolscapes as theory and method and invites further investigations into the ways signage in educational spaces betray language ideologies to either promote or impede bilingual education within school boundaries. Not only does signage communicate language ideologies, it also sends a message about what languages are acceptable by their formal acknowledgment within school confines. For example, bi- or multilingual signage sends a strong message about the formal and hidden curriculum and therefore makes the languages that are deemed official visually explicit (Apple, 2014).

\section{Natural Semantics Metalanguage}

Beyond discourse and spatial analysis, linguistic theory provides a pathway for researchers to derive semantic meaning from the ethos of education. Natural Semantics Metalanguage (NSM) offers a blueprint for linguistic analysis through a systematically identified assemblage of universal prime concepts. The epistemological foundation for NSM is its contention "all languages share a small set of "universal concepts" which can provide a solid basis for cross-cultural understanding" (Goddard \& Wierzbicka, 1995, p. 37). Due to its 
reductionist, culturally neutral approach, NSM is not without its flaws, mostly vis-à-vis a critique of its disregard for "intersubjective differences in conceptualization" and weaknesses in its explanation for aspects of language that lack clear translatability (Blumczyński, 2013, p.265).

Regardless of its limitations, NSM is still regarded as a worthy tool for linguistic analysis by contemporary scholars (Blumczyński, 2013; Geeraerts, 2010). Honegger (in this issue) applies the theory and method of NSM to decode common meanings of the word "education" that undergird liberal and conservative discourses surrounding education and schooling. In his analysis, Honegger notes the ubiquitous use of the term education in reference to specialized fields of teaching and learning, and to education in its institutional form. Going further, Honegger makes a compelling linguistic argument that regardless of their oppositional sociopolitical perspectives on education, conservative and liberal educators, exemplified by the juxtaposed discourses of Paulo Freire and Betsy Devos, are profoundly concerned with institutional weaknesses in public education. Therefore, NSM is a useful framework for distilling semantic explanations to shed light on similarities, as well as differences, in the meaning of pivotal words in discourse that shape ideologies. In doing so, NSM illuminates implicit and explicit socio-cultural biases (Diaz \& Hall, 2020; van Dijk, 1998). For example, the pivotal word education, and its specialized suturing to language for this special issue, allowed for the curation of articles that represent a cluster of related discourses. As described in the next section, asset-based perspectives such as funds of knowledge and funds of identity represent one such cluster of discourses aligned with the theme of this special issue.

\section{Language and Funds of Knowledge/Identity}

Several authors (Adams; Ebersole \& Kanahele-Mossman; Guerra et al., in this issue) discuss the interconnected nature between language, identity, experiences, and accumulations of knowledge from home and community settings. These funds of knowledge can be leveraged by educators to facilitate concept and skill development in the curriculum and to engage families with classroom practices and school-wide endeavors (González, Moll, \& Amanti, 2005; Vélez-Ibáñez \& Greenberg, 1992). Most importantly, language is a foundational aspect of students' and teachers' funds of knowledge. Students' home language embodies their funds of knowledge in its most intimate form as a reflection of familial socialization and as a primary linguistic toolkit to communicate needs, wants, ideas, and worldviews (Keefer et al., 2020). Thus, linguistic funds of knowledge provide an elegant rationale for humanizing pedagogies and translanguaging practices (Adams; Guerra et al., in this issue).

As an extension of funds of knowledge, funds of identity expands upon an individual's home knowledge to include defining experiences and skills often developed beyond home and community settings (Subero,Vujasinović, \& Esteban-Guitart, 2016). Guerra, López, and Benavidez (in this issue) demonstrate the utility of the funds of identity approach in their case study of one Latina teacher's examination of heritage language, mestiza identity, and the ability of humanizing pedagogies to challenge and dismantle internalized deficit-laden perspectives.

As contributing authors (Adams; Guerra et al., in this issue) note, a funds of knowledge/identity approach provides numerous implications for educational policy reform. These implications underscore the importance of valuing students' home/heritage language use, reevaluating evaluation and assessment practices, aligning pedagogical practices so they reflect and leverage the funds of knowledge, skills, and literacies that exist in students' homes and communities (Vélez-Ibáñez \& Greenberg, 1992). Of course, these sage recommendations 
are beholden to political ideologies that drive policy and determine school and classroom practices.

\section{The Intersection of Politics and Language in Educational Contexts}

The intersection of politics and language was examined by several authors in this special issue. To better understand these works we juxtapose their interplay of language and politics with the historical experiences of francophone language speakers in Louisiana. Parker (2019) offers a succinct description of the development of languages, specifically French and English, in Louisiana from pre-Civil War times to the present. During the Antebellum Era, there were various Franco-Caribbean influences on Louisiana and various French-language groups (Cajuns, Creole noir/blanc, Houmas) (Trépanier, 1991). After the Civil War, English speakers began a process of assimilation. In 1916, with the installation of mandatory English-only education, the process of assimilation accelerated (Ancelet, 1988, 2007; Brasseaux, 2005; Klingler, 2003; Parker, 2019). This assimilation was seen as a reflection of patriotism as noted by President Teddy Roosevelt's (1918) praise of lowa's English-only schooling policy when he said "This is a nation - not a polyglot boarding house. There is not room in the country for any 50-50 American, nor can there be but one loyalty - to the Stars and Stripes." This hegemonic ideology is not unlike that which Başok and Sayer (in this issue) discuss when explaining the role of ideology in determining policy and funding for language learning programs at the federal level.

Many heritage language speakers and children of heritage language speakers know the result of English-Only mandatory schooling policy demanded by assimilationist language ideology. Parker (2019) mentioned how French-speaking students in Louisiana were stigmatized and subject to corporal punishment in schools. Ancelet in his nom de plume, Jean Arceneaux (1980) emotes this situation:

I will not speak French on the school grounds.

I will not speak French on the school grounds.

I will not speak French...

I will not speak French...

I will not speak French...

Hé! Ils sont pas bêtes, ces salauds.

Après mille fois, ça commence à pénétrer

Dans n'importe quel esprit.

Ça fait mal; ça fait honte.

Et on ne speak pas French on the school grounds

Et ni anywhere else non plus.

This educational policy of assimilation permeated U.S. society during World War II. In Louisiana, many French-speaking families fully assimilated and lost their heritage language. However, French-speaking soldiers sent to fight in the war returned with renewed pride in their language and culture. This resulted in a "Cajun Renaissance" which had the political effect of the creation in 1968 of the Council for the Development of French in Louisiana (CODOFIL, n.d.). This state agency actively works to promote the French language in Louisiana. In 2011, CODOFIL supported a new mandate for expanding Louisiana's French Immersion programs (Louisiana Legislature, 2011). 
Analysis of a similar renaissance, yet on a micro/individual level, is described in Guerra, López, and Benavidez's article (in this issue) when they discuss the stigmatization of a Latina teacher's heritage, her subsequent learning of her heritage language, and her new dedication to empowering fellow Latino students. Likewise, Stacy, Fernandez, and McGovern (in this issue) describe the creation of a teacher training program, El Instituto, and the repercussions of linguistic stigmatization they encountered during their empowering work with teachers.

\section{What's in a Name: Immersion, Bilingual, Dual Language}

A salient issue that arose when curating these articles was that varied definitions for dual language/immersion/bilingual contexts exist, and these terms are frequently used interchangeably and inconsistently by educators and scholars. Fortune and Tedick (2008) discuss the difficulty of "coming to terms with terminology" in regard to the various terms used to describe dual language/immersion/bilingual education settings (p.3). For example, in the U.S. there exists federal definitions, practitioner terms, and terminology used by researchers for two-way immersion, dual language, dual language immersion, bilingual education, bilingual maintenance, two-way bilingual, and one-way immersion. There are some overarching federal definitions, but these leave much room for interpretation and are not inclusive of all programs. The Department of Health and Human Services does not define contexts as bilingual or dual language, rather they define children's status as language learners:

Dual language learner means a child who is acquiring two or more languages at the same time, or a child who is learning a second language while continuing to develop their first language. The term "dual language learner" may encompass or overlap substantially with other terms frequently used, such as bilingual, English language learner (ELL), Limited English Proficient (LEP), English learner, and children who speak a Language Other Than English (LOTE). (U.S. DHHS, n.d.)

This allows students to be dual language learners, but to be placed in English-only contexts. Which suggests that the program assumes they are developing the first language (L1) at home. Pontier et al. (in this issue) refer to these students in their work. In other words, the context is not necessarily an additive bilingual context, however, it is a context that supports both languages. The Office of English Language Acquisition (OELA) recognized issues exist with definitions. They offered suggestions for terminology in the field as related to instruction in school contexts:

We suggest that the field use the term "dual language" to refer to programs in which instruction is provided in two languages, with the goal of promoting proficiency in both. We suggest that the term "two-way" should be used to describe dual language programs in which roughly equal numbers of students from two language groups (e.g., English speakers and partner language speakers) participate, with the goal of both groups learning both languages. We suggest that the term "one-way" should be used for programs in which predominantly one language group (e.g., language minority students, native English speakers, heritage language learners) participates, with the goal of learning two languages (OELA, 2015, p. xix).

Based on OELA's suggested terms, a program such as a bilingual maintenance program where the students all speak a Language Other Than English (LOTE) and spend part of the day in English and part in the LOTE would be defined as a dual language one-way. However, a context in which all LOTE speakers are learning through both their L1 and the dominant language is 
different from a one-way immersion context in which English-speaking students are learning a new LOTE.

In Utah, the term Dual Language Immersion (DLI), is an umbrella term for either oneway or two-way immersion programs. Utah started an intensive and wide-spread expansion of immersion in 2008 when the International Initiates bill passed to allow for funding of their DLI programs (UtahDLI, n.d.). Because the Utah model is so expansive, including nearly 200 schools in Utah (Utah DLI, n.d.) and their consortium participants in other states such as Delaware and Georgia, their use of DLI as an umbrella term is common. Again, not differentiating for student background becomes an issue. Fortune and Tedick (2008) discuss three types of immersion: (1) one-way for speakers of the majority language, (2) bilingual two-way for speakers of the minority language, and (3) indigenous immersion. Still, there are missing elements. Heritage language speakers, such as those in bilingual maintenance programs where all students speak a LOTE and instruction is one-way do not fit neatly into this model.

Consistent terminology is needed for describing bilingual/immersion contexts that is inclusive of the context of instruction and the LOTE/heritage language status of students. Thus, we propose drawing from all of the above definitions to create a clearer picture of the context, students, and the intensity of immersion. There are dual language immersion one-way (DLI-1) contexts wherein all of the students have the same L1 and are learning the same TL. Within this DLI-1 context, you might have English speakers, such as foreign language one-way that Fortune and Tedick (2008) discuss or DLI-1 dominant. You might have all LOTE speakers, such as a bilingual maintenance class or DLI-1 non-dominant, or have a heritage/indigenous language learners DLI-1 heritage or indigenous. Likewise, a two-way context (DLI-2) in which half the students speak one language, and the other half the other language, could be codified in the same way. A similar codification could be used for a three-way immersion context (DLI-3). The use of a descriptor for both the instructional context, the learners, and the language proportions allows for a better sense of the context (Table 1).

Table 1: Codifying Immersion Contexts and Students

\begin{tabular}{|l|l|l|l|}
\hline Instructional Context & Student Background & $\begin{array}{l}\text { LOTE/Dominant } \\
\text { language proportion }\end{array}$ & Codification \\
\hline $\begin{array}{l}\text { Dual Language } \\
\text { Immersion- one way, } \\
\text { two way }\end{array}$ & $\begin{array}{l}\text { Dominant, non- } \\
\text { dominant, heritage, } \\
\text { indigenous }\end{array}$ & $90 / 10,60 / 40,50 / 50$ & $\begin{array}{l}\text { e.g. DLI-1 heritage } \\
60 / 40\end{array}$ \\
\hline
\end{tabular}

This codification is particularly relevant to understand the context in which students find themselves and the funds of knowledge from which they are drawing. Thus, a rural Louisiana French immersion program would be a DLI-1 dominant, heritage 60/40 program. This term would clarify students are enrolled in a one-way program in which there are English speaking students that are learning the $\mathrm{TL}$, some are heritage language learners, and they spend $60 \%$ of their day in the TL. Compared to the context Chung (in this issue) studied which was a one-way immersion of both dominant and heritage students with a language percentage of 50/50 K-5th grade (DLI-1 dominant, heritage 50/50). Likewise, Pontier et al. (in this issue) and Adams (in this issue) do not study immersion contexts. However, they discuss 
$\mathrm{bi} /$ multilingual contexts where there are bi/multilingual speakers. Using the above terminology, these bi/multilingual educational settings could be clearly differentiated from immersion settings. This would allow policymakers and researchers to tease out the effects of context on the various language learners. This would also help address Valdés' (2018) cautionary notes concerning the effects of DLI-2 on non-dominant language/dialect and heritage language learners.

\section{Cross-fertilization, Contexts, and Theory into Praxis in Teacher Training}

Fortune and Tedick (2008) discussed how divergent language learning contexts can inform each other through the cross-fertilization of effective pedagogies. Within DLI, the use of the above codification can facilitate cross-fertilization through streamlined communication of effective pedagogies across contexts and as opposed to pedagogies that have been identified as context-specific. This context specificity is essential for teacher-educators to be cognizant of when training language educators. This knowledge is also particularly helpful when new frameworks emerge in the field and decisions must be made in regard to when, how, and if to train teachers with these new frameworks. One such framework is the process of translanguaging.

Originally coined to describe systematic planning to teach two languages in a Welsh/English bilingual program (Williams, 1996), translanguaging was later used to describe normal bilingual language usage (García, 2009). Within this issue, four authors reference the use of translanguaging in four different contexts: within a secondary English class (Adams, in this issue), in training dual language teachers (Stacy et al., in this issue), with early childhood English learners (ELS) (Pontier et al., in this issue), and within the context of an adult learning to be bilingual through a heritage language (Guerra et al., in this issue). Within these contexts, the authors view translanguaging as a means to empower and welcome bilinguals into spaces where the dominance of English is pervasive. Yet, numerous scholars question the efficacy of translanguaging in bilingual contexts. For example, Fortune and Tedick (2019) underscored that translanguaging research conducted in immersion contexts fails to provide compelling evidence of its effect on target language acquisition and academic achievement.

When training teachers it is important to by mindful of Delpit's (1995) sage advice that "pretending that gatekeeping points don't exist is to ensure that many students will not pass through them" (p. 39). Before educational practices are endorsed wholeheartedly and included in teacher training, educators need to be aware of whether or not those practices are researchbased. For example, Stacy et al. (in this issue) centered their praxis in a bilingual context where critical professional development and teacher activism met the realities that teachers and students experience. This awareness of the gates through which students must pass is also essential in regard to funding. As Başok and Sayer (in this issue) highlight, if the programs do not meet the academic needs of students, we put funding for language learning programs and their very existence in jeopardy.

Early research on one-way and two-way immersion focused on these gates, namely student outcomes. They found that concurrent language instruction, which translanguaging advocates, results in less time for the LOTE (Legaretta, 1977), decreased student attention to L1 and inattention the TL (Wong Fillmore, 1982), and a lack of linguistic proficiency in the LOTE (Cohen, 1974; Legaretta, 1979). Translanguaging proponents, García and Lin (2016), while they discuss how minoritized languages (LOTE in U.S. schools) must not be isolated, emphasize that 
there must be protection for minority languages. The articles in this issue that address translanguaging do address minority language use, but not student outcomes. The question is how to address those hurdles, protect the minority language, and at the same time build up those elements that translanguaging has been shown to benefit, such as metalinguistic awareness (Garcia-Mateus \& Palmer, 2017), full use of students' linguistic repertoire (Garcia, 2009), and development of students' bilingual identity (Palmer et al., 2014).

Biliteracy activities, such as those Ballinger et al. (2017) propose, are immersion-specific practices that allow the LOTE to benefit from cross-linguistic analysis while maintaining a separate, safe place for the language. Furthermore, Lyster et al. (2013) found this approach benefits students' acquisition of the LOTE. In its simplest form, biliteracy activities are instructional strategies that utilize L1/TL literature to compare and contrast linguistic features between the TL and the LOTE. Additionally, literature-based elements of these activities allow teachers to tailor instructional literature to non-dominant, heritage, and indigenous immersion student populations. This simple strategy is a form of translanguaging that proponents of separation of languages can endorse. Biliteracy pedagogies are also exemplary of the crossfertilization that Fortune and Tedick (2008) promote.

\section{Conclusion}

We hope this special issue will facilitate cross-fertilization within related fields of language and education. Among the spheres of language in educational contexts there exists overlapping and fruitful discourses in language theories, research methods, critical pedagogies, and dynamic interactions in educational spaces. Political ideologies continue to influence the fiscal realities of language programs in schools and reflect the values and beliefs within society. Thus, cross-fertilized studies have the capacity to inform policies that drive funding and the nature of language education. The consequences of language-related education policies are profound because they determine whether or not the needs of language learners are met. These needs include, but are not limited to, students' academic, linguistic, economic, and sociopsychological needs. Yet, the importance of language in educational contexts extends beyond language learning as a signifier of ethnicity, race, immigrant status, social class, and gender. Educators need to beware of the power of deficit-laden discourses to stigmatize and exclude students' funds of knowledge and identity from educational spaces. In contrast, language can also be used by educators to inspire and empower students, families, and communities through the resistance of oppressive forces in society.

\section{References}

Ancelet, B. J. (1988). A perspective on teaching the "problem language" in Louisiana. The French Review, 61(3), 345- 356.

Ancelet, B. J. (2007). Negotiating the mainstream: The Creoles and Cajuns in Louisiana. The French Review, 80(6), 1235-1255.

Apple, M. (2014). Official knowledge: Democratic knowledge in a conservative age (3rd ed.). Routledge.

Arceneaux, J. (1980) Schizophrénie linguistique, in J. Arceneaux, \& D. Clifton, (Eds.) Cris sur le Bayou: Naissance d'une poésie acadienne en Louisiane (pp. 15-66). Intermède. 
Ballinger, S., Lyster, R., Sterzuk, A., \& Genesee, F. (2017). Context-appropriate crosslinguistic pedagogy. Journal of Immersion \& Content-Based Language Education, 5(1), 30-57.

Blommaert, J. (2013). Ethnography, superdiversity and linguistic landscapes: Chronicles of complexity. Multilingual Matters.

Blumczyński, P. (2013). Turning the tide: A critique of Natural Semantic Metalanguage from a translation studies perspective. Translation Studies, 6(3), 261-276.

Brasseaux, C. (2005). French, Cajun, Creole, Houma: A primer on Francophone Louisiana. Louisiana State University Press.

CODOFIL. (n.d.). French in Louisiana timeline. CODOFIL website. Retrieved

from:https://www.crt.state.la.us/cultural-development/codofil/about/french-inlouisiana/timeline/index

Cohen, A. (1974). The Culver City Spanish Immersion Program: The First Two Years. The Modern Language Journal, 58(3), 95-103. Retrieved December 20, 2020, from http://www.jstor.org/stable/323824

Council for the Development of French in Louisiana, RS 25:651, Louisiana Legislature, (2011). Retrieved from: https://legis.la.gov/Legis/Law.aspx?d=84519

Delpit, L. (1995). Other people's children: Cultural conflict in the classroom. New Press.

Diaz, B. A., \& Hall, M. K. (2020). A corpus-driven exploration of U.S. language planning and language ideology from 2013 to 2018. Journal of Language and Politics, 19(6), 916937.

Fairclough, N. (2013). Critical discourse analysis: The critical study of language. Routledge.

Fortune, T. W., \& Tedick, D. J. (2008). One-way, two-way, and indigenous immersion: A call for cross-Fertilization: Evolving perspectives on immersion education. In T. W. Fortune, \& D. J. Tedick (Eds.), Pathways to multilingualism: Evolving perspectives on immersion education (pp. 3-21). Multilingual Matters.

Fortune, T. W., \& Tedick, D. J. (2019). Context matters: Translanguaging and language immersion in the U.S. and Canada. In M. Haneda, \& H. Nassaji (Eds.), Perspectives on language as action (pp 27-44). Multilingual Matters.

García, O. (2009). Bilingual education in the 21st century: A global perspective. WileyBlackwell.

García, O. \& Lin, A. (2016). Translanguaging and bilingual education. In O. García, A. Lin, \& S. May (Eds.), Bilingual and multilingual education (pp. 117-130). Springer.

García-Mateus, S., \& Palmer, D. (2017). Translanguaging Pedagogies for Positive Identities in Two-Way Dual Language Bilingual Education. Journal of Language, Identity, and Education, 16(4), 245-255.

Geeraerts, D. (2010). Theories of lexical semantics. Oxford University Press.

Goddard, C., \& Wierzbicka, A. (1995). Key words, culture and cognition. Philosophica, 55(1), 37-67.

González, N., Moll, L., \& Amanti, C. (2005). Funds of knowledge: Theorizing practices in households, communities and classrooms. Lawrence Erlbaum Associates.

Gorski, P. S. (2008) The myth of the culture of poverty. Educational Leadership, 67(7), 32-36.

Gorter, D. (2018). Linguistic landscapes and trends in the study of schoolscapes. Linguistics and education, 44, 80-85.

Haj-Broussard, M., Keefer, N., Hebert, D., \& Grivet, C. (2019). Conversations in Immersion: Concerns about Pedagogy and Gatekeepers. NECTFL Review, 84, 35-61. 
Keefer, N., Lopez, J., Young, J., \& Haj-Broussard, M. (2020). Gathering funds of knowledge: An elementary social studies unit plan for bilingual settings. Social Studies and the Young Learner, 33(2), 14-19.

Klingler, T. A. (2003). Language labels and language use among Cajuns and Creoles in Louisiana. University of Pennsylvania Working Papers in Linguistics, 9(2), 77-90.

Landry, R., \& Bourhis, R. (1997). Linguistic landscape and ethnolinguistic vitality: An empirical study. Journal of Language and Social Psychology, 16(1), 23-49.

Legretta, D. (1977) Language choice in bilingual classrooms. TESOL Quarterly, 11, 9-16.

Lyster, R., Quiroga, J., \& Ballinger, S. (2013). The effects of biliteracy instruction on morphological awareness. Journal of Immersion and Content-Based Language Education, 1(2), 169-197. doi: 10.1075/jicb.1.2.02lys

Palmer, D. K., Martínez, R. A., Mateus, S. G., \& Henderson, K. (2014). Reframing the Debate on Language Separation: Toward a Vision for Translanguaging Pedagogies in the Dual Language Classroom. Modern Language Journal, 98(3), 757-772.

Parker, J. L. (2019). Second language learning and cultural identity: Reconceptualizing the French curriculum in Louisiana colleges and universities. Journal of Curriculum Studies Research, 1(1), 33-42.

Rogers, R., Malancharuvil-Berkes, E. Mosley, M., Hui, D., \& O’Garro, G. (2005). Critical discourse analysis in education: A review of the literature. Review of Educational Research, 75(3), 365-416.

Roosevelt, T. (1918, May 27th) Speech about English-only schooling policy. Iowa.

Sensoy, Ö., DiAngelo, R. (2017). Is everyone really equal? An introduction to key concepts in social justice education ( $2^{\text {nd }}$ ed.). Teachers College Press.

Soland, J. (2019). English language learners, self-efficacy, and the achievement gap. The Collaborative for Student Growth at NWEA Research Brief.

Subero, D., Vujasinović, E., \& Esteban-Guitart, M. (2016). Mobilising funds of identity in and out of school. Cambridge Journal of Education, 47(2), 247-263.

Trépanier, C. (1991). The Cajunization of French Louisiana: Forging a Regional Identity. The Geographical Journal, 157(2), 161-171. doi:10.2307/635273

Woolard, K.A., \& Schieffelin, B.B. (1994). Language ideology. Annual Review of Anthropology, 23(1), 55-82.

United States Department of Health and Human Resources (n.d.). Head Start performance standards. Part 1305.2 --definitions. https://eclkc.ohs.acf.hhs.gov/policy/45-cfr-chapxiii/1305-2-terms

Utah Dual Language Immersion (n.d.). Why Immersion? http://utahdli.org/whyimmersion.html

Utah Dual Language Immersion (n.d.). Participating Schools. http://utahdli.org/participatingschools.html

Valdés, G. (2018). Analyzing the curricularization of language in two-way immersion education: Restating two cautionary notes. Bilingual Research Journal, 41(4), 388-412. DOI: $10.1080 / 15235882.2018 .1539886$

van Dijk, T. (1998). Ideology: A multidisciplinary approach. Sage Publications. 
Vélez-Ibáñez, C.G., \& Greenberg, J.B. (1992). Formation and transformation of funds of knowledge among U.S.-Mexican households. Anthropology \& Education Quarterly, 23(4), 313-335.

Williams, C. (1996) Secondary Education: Teaching in the bilingual situation. In C.Williams, G. Lewis, and C. Baker (eds.) The language policy: Taking stock (pp. 39-79). CAl.

Webster, A. (2014). DIF'G'ONE' AND SEMIOTIC CALQUING: A Signography of the Linguistic Landscape of the Navajo Nation. Journal of Anthropological Research, 70(3), 385-410. Wong Fillmore, L. (1982) Instructional language as linguistic input: Second language learning in classrooms. In L.C. Wilkinson (ed.) Communicating in the classroom (pp.283-294). Academic Press. 